\title{
Altered expression of miRNAs in a dihydrotestosterone-induced rat PCOS model
}

\author{
Md Munir Hossain ${ }^{1,2}$, Mingju Cao ${ }^{3}$, Qi Wang ${ }^{3}$, Ji Young Kim³ ${ }^{3}$ Karl Schellander ${ }^{1}$, Dawit Tesfaye ${ }^{1}$ \\ and Benjamin K Tsang ${ }^{3,4,5^{*}}$
}

\begin{abstract}
Background: The polycystic ovary syndrome (PCOS) is a complex and heterogeneous endocrine condition characterized by hyperandrogenism, hyperinsulinemia, insulin resistance and chronic anovulation. Regulation and interaction of a multitude of genes required for follicular development are found to be altered in PCOS. MicroRNAs (miRNAs) mediate posttranscriptional gene regulation by binding to the $3^{\prime}$ untranslated region of mRNAs to either inhibit or enhance translation. However, the extent and regulation of miRNA expression in PCOS is poorly understood and the current study is the first to describe altered expression of miRNAs in PCOS.
\end{abstract}

Methods: A chronically androgenized [5a-dihydrotestosterone (DHT)-treated] rat model which recapitulates many of the phenotypes of human PCOS, and miRNA PCR array was used to investigate the expression of 349 miRNAs in DHT treated rat ovaries. The ovarian expression of several selected miRNAs was also analyzed by in situ localization experiment.

Results: DHT-treated rats exhibit increased body weight, disrupted estrus cyclicity, decreased insulin sensitivity and decreased ovarian weight, with the latter phenomenon readily rescued by gonadotropin treatment in vivo. In general, 24\% of the 349 miRNAs investigated were found to be differentially expressed between DHT-treated and control rats. Most of the differentially expressed miRNAs were found to be predominantly localized in the theca cells of the follicles. In silico analysis of the potential target genes of dysregulated miRNAs revealed their possible involvement in various pathways in the regulation of ovarian function.

Conclusion: Our current findings suggest that miRNAs are differentially regulated in hyperandrogenism, a condition possibly involved in the dysregulation of steroid hormone receptors and intra-ovarian factors, and that miRNAs may be involved in the etiology of PCOS.

Keywords: PCOS, miRNA, Dihydrotestosterone

\section{Introduction}

Polycystic ovary syndrome (PCOS), a multi-factorial endocrine condition, affects up to $5-10 \%$ of women in reproductive age and accounts for $75 \%$ of anovulatory infertility [1-3]. PCOS is a heterogeneous syndrome with complex pathologies with follicle growth arrest at the

\footnotetext{
*Correspondence: btsang@ohri.ca

${ }^{3}$ Reproductive Biology Unit and Division of Reproductive Medicine, Department of Obstetrics \& Gynecology and Cellular \& Molecular Medicine, University of Ottawa; Chronic Disease Program, Ottawa Hospital Research Institute, The Ottawa Hospital (General Campus), Ottawa, ON K1H 8L6, Canada

${ }^{4}$ World Class University Major in Biomodulation, Department of Agricultural Biotechnology, College of Agriculture and Life Sciences, Seoul National University, Seoul 151-921, Republic of Korea

Full list of author information is available at the end of the article
}

small antral stage, minimal granulosa cell proliferation, hyperthecosis and hyperandrogenemia, and chronic anovulation [1]. It is associated not only with infertility, but also with increased risk of metabolic disorders, such as insulin resistance, diabetes, obesity, and cardiovascular diseases [4]. Both genetic and environmental factors are known to contribute to the pathogenesis of PCOS; however, its etiology is unclear.

Differential gene expression is evidenced in human PCOS ovaries when compared to the normal ones [5]. Genomic studies in PCOS have revealed a variety of altered genes that fall into many functional categories, including cell division, apoptosis and regulation of gene expression and metabolism. While genes involved in
C Biomed Central

(C) 2013 Hossain et al.; licensee BioMed Central Ltd. This is an Open Access article distributed under the terms of the Creative Commons Attribution License (http://creativecommons.org/licenses/by/2.0), which permits unrestricted use, distribution, and reproduction in any medium, provided the original work is properly cited. 
steroidogenesis, including those related to retinoic acid biosynthesis and luteinizing hormone-responsive gene, are generally up-regulated in theca cells of PCOS subjects [6], those associated with Wnt signalling and ovarian folliculogenesis appear to be down-regulated [7,8]. Although ovarian apoptotic genes are altered in PCOS, the net effect of these changes is unclear [7]. In addition, significant differences in mRNA abundance in oocytes from PCOS patients have also been reported and cluster analysis of 374 genes indicated an association with chromosomal alignment and segregation in mitosis and/or meiosis [9].

Despite ample evidences on gene dysregulation in PCOS ovary as reported above, precisely how these genes are transcriptional and post-transcriptional regulated is poorly understood. New advances in posttranscriptional gene regulation have resulted from the discovery of hundreds of miRNAs in different mammalian species. Diverse expression pattern of miRNAs and the high abundance of potential targets in the ovary have led to the notion of their importance in the regulation of ovarian function. A large number of miRNAs has now been identified in the ovary $[10,11]$ and found to be regulated by gonadotropins during follicular development $[12,13]$. Recent studies indicate that miRNAs are involved in the regulation of steriodogenesis, cell proliferation and apoptosis in human granulosa cells [14,15]. Differential expression of miR-23a, miR-23b,miR-542-3p, miR-211, and miR-17-5p in granulosa/cumulus cells from women undergoing assisted reproduction suggests aberrant miRNA expression may be an underlying etiology in female infertility $[16,17]$. Furthermore, miRNAs have been implicated to play a role in obesity and metabolic syndrome, including insulin resistance [18], conditions often associated with PCOS. However, whether miRNAs contribute to the follicle arrest, dysregulated steroid production and insulin resistance in PCOS is not known. Understanding how miRNAs are regulated in the ovary and the identification of their specific targets and functions may offer novel insights into the etiology of PCOS and the development of target-specific gene regulation for its treatment.

Hyperandrogenism is one key feature in human PCOS patients and circulating levels of androgens, such as testosterone, androstenedione and dihydrotestosterone (DHT), are elevated in these patients $[19,20]$. A number of animal models have been developed that allow one to focus on different aspects of PCOS pathology, including ovarian follicular and metabolic features [21-23]. A recent report on a rat PCOS model involving chronic DHT implant mimics the hyperandrogenic status and exhibits both polycystic ovaries and metabolic abnormalities similar to those in human PCOS [23], allowing one to examine not only ovarian characteristics but also metabolic features of PCOS.
We hypothesize that PCOS is associated with dysregulation of ovarian miRNAs which may be involved in post-transcriptional regulation of genes involved in the ovarian pathology. Taking advantage of DHT-induced rat PCOS model, we tested this hypothesis by comparing the expression of 349 miRNAs between DHT-treated vs untreated rat ovaries. Moreover, selected candidate miRNAs were investigated for their localization in follicular cells. Results of the present study revealed that PCOS is associated with differential expression of regulatory non-coding miRNAs in rat ovaries.

\section{Materials and methods}

\section{DHT-filled silastic capsules preparation}

The DHT-filled capsules were prepared as previously described [24]. Silastic tubing (I.D. $1.98 \mathrm{~mm}$ x O.D. $3.18 \mathrm{~mm}$; Dow Corning, Cat. No. 2415577, Midland, MI), cut to an appropriate length to achieve a desired surface area of $299.70 \mathrm{~mm}^{2}$, was filled with DHT (Sigma) from $1 \mathrm{ml} \mathrm{syr-}$ inge. The tubing was closed at each end $(3 \mathrm{~mm})$ with a sealant (Silicone Type A, Dow Corning Cat. No. 891, Midland, MI), ensuring that adhesive is in contact with tubing walls and that there are no air bubbles. Control capsules were empty with only sealant on both ends. After overnight dry, capsules were rinsed for 2 days in $3 \%$ bovine serum albumin (BSA) in phosphate buffer saline (PBS) with $0.1 \% \mathrm{NaN}_{3}$ solution, thoroughly washed with PBS and sterilized by dipping briefly in $70 \%$ ethanol before use.

\section{Animal preparation}

Sprague Dawley rats (Charles River, Montreal, Canada) were maintained on 12-h light, 12-h dark cycles and given food and water ad libitum. All procedures were carried out in accordance with the Guidelines for the Care and Use of Laboratory Animals, Canadian Council on Animal Care, and were approved by University of Ottawa and Ottawa Hospital Research Institute Animal Care Committee.

\section{Animal surgery, DHT capsule implantation and animal care} Thirty-six female rats at 21 days of age were randomly divided into two groups (control vs. DHT group) and were implanted with a DHT-filled silicone capsule continuous-releasing (83 $\mu \mathrm{g}$ per day; empty capsule for controls) for 12 weeks to mimic the hyperandrogenic state in women with PCOS, whose plasma DHT levels are approximately 1.7-fold higher than those of healthy control [23]. Animals were weighed weekly to monitor body weight gain and euthanized at 12 wks postimplantation. Ovaries were collected for analyses.

\section{Determination of estrous cycle phases of rat}

The estrous cycle of rats was monitored by microscopic analysis of vaginal smear obtained every morning for 12 
days from 10-11 wks post-implantation. Predominant cells associated with each phase of the estrus cycle were: epithelial cells (proestrous; P), enucleated cornified cells (estrous; E), equal mix of leukocytes and cornified epithelial cells (metestrous; M) and leukocytes (diestrous; D) [25].

\section{Determination of insulin sensitivity}

Insulin sensitivity test (IST) was performed after $12 \mathrm{~h}$ overnight fasting at 10 wks of surgery. Human insulin (0.2 U/100 g body weight intravenously, Novo Nordisk Canada Inc. Mississauga, ON, Canada) was administered to control or DHT-treated rats through tail vein and blood samples were obtained from the tail at $0,5,10,20$, 40, 80, $160 \mathrm{~min}$. after insulin injection. Glucose levels were determined by glucose test strips (ACCU-CHEK, Roche). The insulin sensitivity index $K_{I T T}$ was calculated from the slope of a linear portion of the regression line of natural logarithm of glucose versus time. Raw data were transformed by $\log K_{I T T}$ for analysis. $K_{I T T}=$ $\left(0.693 / t_{1 / 2}\right) \times 100, t_{1 / 2}$ represents the half-life of glucose decay after insulin injection [26].

\section{Ovarian tissue collection and morphological evaluation}

Pairs of ovaries were excised, and weighed. For morphological evaluation, whole ovaries were embedded in paraffin block and longitudinal sections ( $4 \mu \mathrm{m}$ thick) were stained with hematoxylin and eosin. Since the considerable discrepancy in estimating follicle numbers exists between studies due to different section thickness and correction factors adopted [27], the percentage of number of cystic follicles (FC) and corpus lutea (CL) over total follicular structure (including all kinds of follicles and $\mathrm{CL}$ ) per ovary were determined. A FC was defined as an collapsed anovulatory follicle exhibiting the absence of oocyte, reduced granulosa cell layer, but intact theca layer. The maximal longitudinal ovarian sections were investigated to count the numbers of FC and CL, mean of the percentage of FC and CL from 3-5 sections after sampling every fifth section were defined as the relative values per ovary from 5 individual animals. In an additional experiment, three rats from DHT group at each time point were administered with 20 IU of equine chorionic gonadotropin (eCG; Sigma; PBS as control) for designated time $(0-30 \mathrm{~h})$ to test their ovarian responsiveness to gonadotropin in vivo.

\section{miRNA expression profiling}

Ovarian cortex tissues were snap-frozen in liquid nitrogen and stored at $-80^{\circ} \mathrm{C}$ until analysis. Total RNAs including small RNAs from 3 independent DHT (DHT1-3) treated and 3 non-treated control (CTL1-3) ovaries have been isolated using miRNeasy mini kit (Qiagen, Hilden, Germany) following manufacturer's protocol. Immediately after isolation, contaminating DNA and divalent cations from the
RNA samples were removed using TURBO DNA-free ${ }^{\mathrm{Tm}} \mathrm{kit}$ (Ambion, Foster City, CA) according to instruction of the manufacturer. The quality and the concentration of the RNA samples were assessed by NanoDrop 8000 spectrophotometer (NanoDrop, Wilmington, Delaware, USA). Subsequently, a total of $250 \mathrm{ng}$ purified RNA from each samples were reverse transcribed for qPCR analysis, using the QuantiMir ${ }^{\mathrm{TM}}$ RT systems (System Biosciences, Mountain View, CA).

MiRNA expression analysis was performed using miRNA PCR array platform containing 349 well characterized Rat miRNAs including 3 endogenous controls, namely Rat U6 snRNA, RNU43 snoRNA \& U1 snRNA (System Biosciences, Mountain View, CA, Cat \# RA680A-1) according to the user manual of miRNome microRNA Profilers QuantiMir ${ }^{\mathrm{rat}}$ (System Biosciences, Mountain View, CA) with some modifications. Briefly, $20 \mu \mathrm{l}$ of cDNA from each sample mixed with $1300 \mu \mathrm{l}$ of Maxima 2x SYBR Green, (Fermentas Gmbh, Leon-Rot, Germany, Cat \# K0222), $50 \mu \mathrm{l}$ of universal reverse primer and $800 \mu \mathrm{l}$ of nuclease-free water. Five microlitres of mixed cDNA cocktail were dispersed into each well of 384 well PCR plate containing $1 \mu \mathrm{l}$ of pre-aliquoted miRNA specific primer. Multichannel laboratory automation workstation was used for pipetting the mix and mixing the reaction into 384 well plates $\left(\right.$ Biomek $^{\odot} \mathrm{NX}^{\mathrm{P}}$, Beckman Coulter, Krefeld, Germany). The assays were performed in ABI 7900 HT real time PCR system (Applied Biosystems, Foster City, CA, USA) with thermal cycling programme at $52^{\circ} \mathrm{C}$ for $2 \mathrm{~min}, 95^{\circ} \mathrm{C}$ for $10 \mathrm{~min}$, 40 cycles of $\left(95^{\circ} \mathrm{C}\right.$ for $15 \mathrm{sec}, 60^{\circ} \mathrm{C}$ for $\left.1 \mathrm{~min}\right)$. Dissociation stage was included at the end of the programme to assess the Tm of the PCR amplicons and to verify the specificity of the amplification reactions. In addition, amplification was verified for randomly selected reactions through $2.5 \%$ agarose gel electrophoresis. Data were analysed by $\Delta \Delta C_{t}$ method and normalized by the geometric mean of the three endogenous controls through System Bioscience's free Software developed to analyse PCR Array data for Rat miRNome (System Biosciences, Mountain View, CA), equipped with t test. A fold regulation of $\geq 2$. $\mathrm{P} \leq 0.05$ was considered as significant in expression differences.

\section{Localization of selected miRNAs in ovarian cryo-section}

Ovaries were fixed in $4 \%$ paraformaldehyde $\left(\mathrm{pH} 7.3 ; 4^{\circ} \mathrm{C}\right.$, overnight) followed by incubation in $0.5 \mathrm{M}$ Sucrose in DEPC-treated $1 \mathrm{X}$ PBS ( $4^{\circ} \mathrm{C}$, overnight). They were embedded in Tissue-Tek Oct reagent (Shandon Cryomatrix, Thermo Cat\# 6769006) in a tissue path base mold, underwent a slow freezing process $\left(-1^{\circ} \mathrm{C} / \mathrm{min}\right.$ rate $)$ in a freezing container (NALGENE ${ }^{\mathrm{TM}}$ Cryo, Cat\# 5100-0001). Serial ovarian sections $(10 \mu \mathrm{m})$ were cut at $-23^{\circ} \mathrm{C}$ using rapid sectioning cryostat (Leica microsystem Nussloch $\mathrm{GmbH}$, 


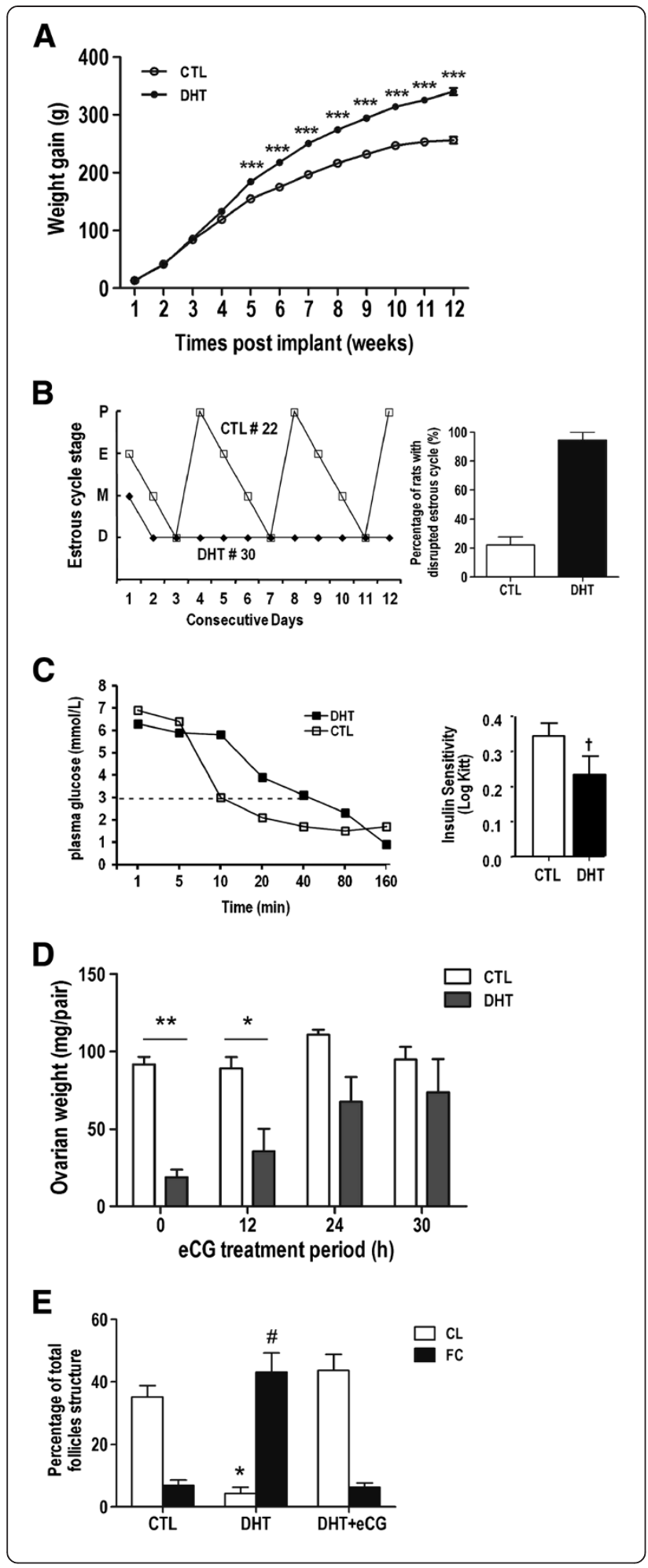

Figure 1 DHT-treated rats show higher body weight gain, disrupted estrous cycles, insulin resistance, responsiveness to gonadotropin and ovarian features. (A) Weight gain of DHTtreated rats are significantly higher than CTL animals after 5 weeks DHT implant (***, P < 0.001). (B) Estrous cycle was evaluated by microscopic analysis of the predominant cell type in vaginal smears obtained daily from 10-11 weeks post-implantation. Estrous cycle patterns were shown in two representative rats from each group. P: proestrous; E: estrous; M: metestrous; D: diestrous. $94 \%$ of DHT-treated rats show irregular estrous cycle versus $22 \%$ in CTL rats. (C) Insulin Sensitivity Test (IST): Animals were injected with insulin (0.2U/100g Body weight) through tail vein and plasma glucose levels were measured by glucose meter at the time indicated. Data was transformed by Log $K_{\Pi T T}$ for analysis. $K_{\Pi T T}=0.693 / t_{1 / 2} \times 100, t_{1 / 2}$ represents the half-life of glucose decay after insulin injection $(+P<0.05)$. (D) $20 \mathrm{IU}$ eCG was injected to DHT-treated rats for designated time ( $0-30 \mathrm{~h})$ and ovarian weight was assessed. Reduced ovarian weight in DHT-treated rats was reversed by eCG treatment in vivo (*, $\mathrm{P}<0.05 ;{ }^{* *} \mathrm{P}<0.01$ ). (E) Corpus luteum and cystic follicle numbers were counted in the maximal longitudinal ovarian sections and percentage of $\mathrm{FC}$ or $\mathrm{CL}$ over the total follicle structure per section were presented. Data showed that PCOS rats was bearing large number of cystic follicles accompanying with anovulation (CL percentage in control vs DHT was 35\%,4\%, ${ }^{*} \mathrm{P}<0.05$; cystic follicles (FC) was $7 \%$ vs $43 \%$, respectively, \# $\mathrm{P}<0.05$ ).

Heidelberger, Germany) and mounted on SuperFrost ${ }^{\circ}$ Plus slides (Menzel-Glaeser, Germany) at $-80^{\circ} \mathrm{C}$ until hybridization began. Sections were checked for quality and required cell content at a regular interval by staining with $\mathrm{TB}$ in a light microscope. Post-fixation, acetylation and proteinase $\mathrm{K}$ treatment was done as described previously [28]. Two hours of pre-hybridization was performed at $52^{\circ} \mathrm{C}$ in hybridization solution (50\% formamide, $5 \mathrm{x}$ sodium chloride/sodium citrate [SSC; pH 6.0], 0.1\% Tween-20, $50 \mu \mathrm{g} / \mathrm{ml}$ heparin, and $500 \mathrm{mg} / \mathrm{ml}$ yeast tRNA). Ovarian sections were incubated overnight at $52^{\circ} \mathrm{C}$ in a hybridization buffer containing 3'-Digoxigenin (DIG) labeled LNA-modified oligonucleotide probes (1pM) for miRNA, U6 RNA and scrambled miRNA (Exiqon, Vedbaek, Denmark) in a humidified chamber. Blocking, incubation with anti-DIG-AP antibody, washing and color development with alkaline phosphatase substrates solution [5-Bromo-4-chloro-3indolyl phosphate/Nitro blue tetrazolium (BCIP/NBT)] were performed as described previously [28]. Vector ${ }^{\circ} \mathrm{Me}-$ thyl Green (Vector laboratories, Burlingame, CA) was used as nuclear counter-stain.

\section{Statistical analyses}

All data were analyzed using Prism 5.0 statistical software (GraphPad, San Diego, CA). The results were presented as means \pm SEM as detailed in figure legends. Differences in body weight gains, follicle cysts and corpus luteum percentage were analyzed by two-way ANOVA, ovarian weight between groups were analyzed by one-way ANOVA and followed by Bonferroni posthoc test. Insulin sensitivity in PCOS and control groups 
was compared by Student t-test. Statistical significant difference was defined at $\mathrm{P}<0.05$.

\section{Results}

Characterisation of PCOS rat model

Body weight increased in PCOS rats

Body weight for individual animal was weighed weekly. As shown in Figure 1A, weight gain in DHT-treated rats was significantly higher than control animals over the experimental period $(340.32 \pm 20.66$ vs. $256.49 \pm 21.31 \mathrm{~g}, \mathrm{~N}=18$, $\mathrm{P}<0.001)$, beginning at 5 weeks after implantation.

\section{Irregularity in estrous cycle in DHT-treated rat}

Estrous cycle was evaluated by microscopic analysis of the predominant cell type in vaginal smears obtained daily from 10-11 weeks post-implantation. Estrous cycle pattern in a representative rat from each group is shown (Figure 1B). During 12 days of evaluation, control rat \# 22 had 3 regular estrous cycles, whereas DHT-treated rat \# 30 started at metestrous and then showed prolong diestrous phase. $94 \%$ of animals in DHT group shown disrupted estrous cycle compared to $22 \%$ of animals in control group (Figure 1B, $\mathrm{P}<0.001, \mathrm{~N}=17$ ).

\section{DHT-treated rats showed insulin resistance}

In order to examine the metabolic phenotype of rats which received DHT, insulin sensitivity test was performed. Rat plasma glucose levels were determined by glucose test strips after insulin challenge. The insulin sensitivity index $K_{I T T}$ was calculated and a lower $K_{I T T}$ suggests decreased insulin sensitivity or insulin resistance [26]. Our data shows reduced insulin sensitivity in DHT-treated rats compared to control (Control rats $\log K_{I T T}=0.34 \pm 0.03$ vs. DHT-treated rats $0.23 \pm 0.05$, $\mathrm{N}=17, \mathrm{P}<0.05$ ) (Figure 1C). As indicated as dotted line in Figure 1C, it took 10 minutes for the Control rat \# 12 to change the basal glucose level from $6.9 \mathrm{mmol} / \mathrm{L}$ to $3 \mathrm{mmol} / \mathrm{L}$, whereas it took 40 minutes for the glucose levels of DHT-treated rat \# 5 to decrease from 6.3 to 3 $\mathrm{mmol} / \mathrm{L}$. A glucose curve shift to the right was evident in DHT-treated rats when compared to control animals.

\section{Ovary weights were lower in DHT-treated rats}

Pair ovary weight in DHT-treated rats was significantly lower than their control counterparts $(0 \mathrm{~h}: 18.93 \pm 4.85$ mg vs. $91.90 \pm 4.48 \mathrm{mg}$. $\mathrm{P}<0.001$ ) (Figure 1D). To test if DHT-treated ovaries are responsive to gonadotropin, three DHT-treated rats per group were administered with $20 \mathrm{IU}$ of eCG (PBS as control) for designated time (0-30 h) and the ovaries were weighed in an additional experiment. Interestingly, the reduction of ovary weight in DHTtreated rats was markedly rescued with longer eCG treatment, indicating that this PCOS phenotype was responsive to gonadotropin (Figure 1D).

\section{DHT-treated rats exhibited anovulation}

To assess ovarian feature of PCOS rat, ovarian morphology in sections from CTL or DHT-treated rats was examined by $H \& E$ staining. Percentage of cystic follicle (FC) and corpus luteum (CL) over the total follicular structure were estimated in the longitudinal ovarian sections, as described in Materials and Methods. Estimation of relative value of FC and CL number, regardless of the total follicle numbers and their stages, is sufficient to evaluate disruption of ovarian follicular development as seen in PCOS. In control rat, CL accounted for $35 \%$ of total follicular structure per section, whereas those in DHT-treated rats were $4.3 \%$ (Figure $1 \mathrm{E}, \mathrm{P}<0.05$ ). In contrast, follicle cysts in DHT-treated rats accounted for $43 \%$ of total follicle structure, which was significantly higher than in control rat $(7 \%)(\mathrm{P}<0.05)$. Gonadotropin treatment reactivated follicular development in the cystic ovaries and induced ovulation, as the presence of CL increased to $43.6 \%$ in eCG-treated rats, while FC percentage declined to $6.3 \%$ over the total follicle structure (Figure 1E).

\section{Differential expression of miRNAs in the rat PCOS}

Among the 346 miRNAs analysed, 25 miRNAs were found to be highly expressed in the normal ovary when compared to the expression level of other miRNAs (Figure 2). Most of these 25 miRNAs were also found to be highly expressed in DHT-treated ovary, although the extent of their expression was different compared to the normal ovary. Thus, the highly expressed miRNAs in control or DHT-treated ovary may be designated as ovarian miRNAs. These include rno-miR-195, rno-miR-125a-5p, rno-let-7a, rno-miR-16, rno-miR-30b-5p, rno-let-7c, rnolet-7b, rno-miR-125b-5p, rno-miR-221, rno-miR-222, rno-miR-26a, rno-miR-322, rno-miR-23a, rno-miR-191, rno-miR-30 family, rno-miR-21, rno-miR-126, rnomiR-23b, rno-miR-145 and rno-miR-494.

Expression of 346 miRNAs in ovaries of DHT-treated and control rats were compared and a fold change of 2 or more and with the $\mathrm{P}$ values equal to or less than 0.05 were considered statistically significant. In general, $24 \%$ miRNAs were differentially expressed between DHT and CTR ovary. Among the differentially expressed miRNAs, most of the miRNAs (80\%) were evidenced as over-expressed in DHT ovary. A total of 17 and 72 miRNAs were found to be down- and up-regulated, respectively in DHT compared to the CTL ovary (Figure 3). A list of differentially expressed miRNAs (Fold change $\geq 2$ and their corresponding P value) is presented in Figure 4. Beside this group, miRNAs which were also highly abundant in DHT-treated ovaries are 


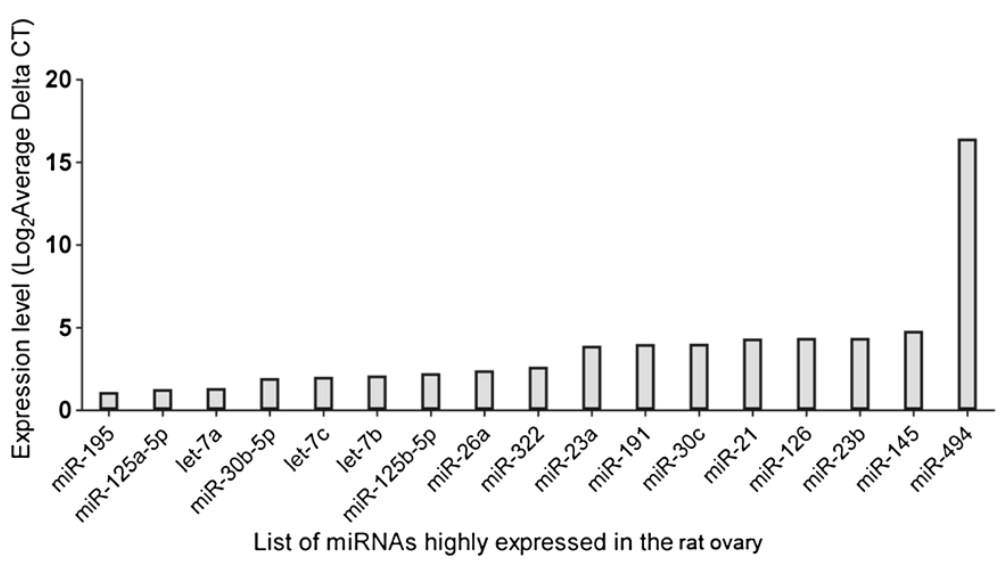

Figure 2 MiRNAs predominantly expressed in normal rat ovary compared to the expression level of other miRNAs.

rno-miR-221, rno-miR-222, rno-miR-25, rno-miR-26b, rno-miR-379\%, rno-let-7d, rno-miR-24, rno-miR-673, rnomiR-26b, rno-miR-335, rno-miR-382\%, rno-miR-412, rnomiR-99a*, rno-miR-543, rno-miR-674-3p, rno-miR-409-3p. MiRNAs found to be primarily down-regulated in DHT-treated rats includes rno-miR-770, rno-miR-466c, rno-miR-21, rno-miR-31, rno-miR-182, rno-miR-183, rno-miR-96, rno-miR-132, rno-miR-182, rno-miR-384-3p and rno-miR-184.

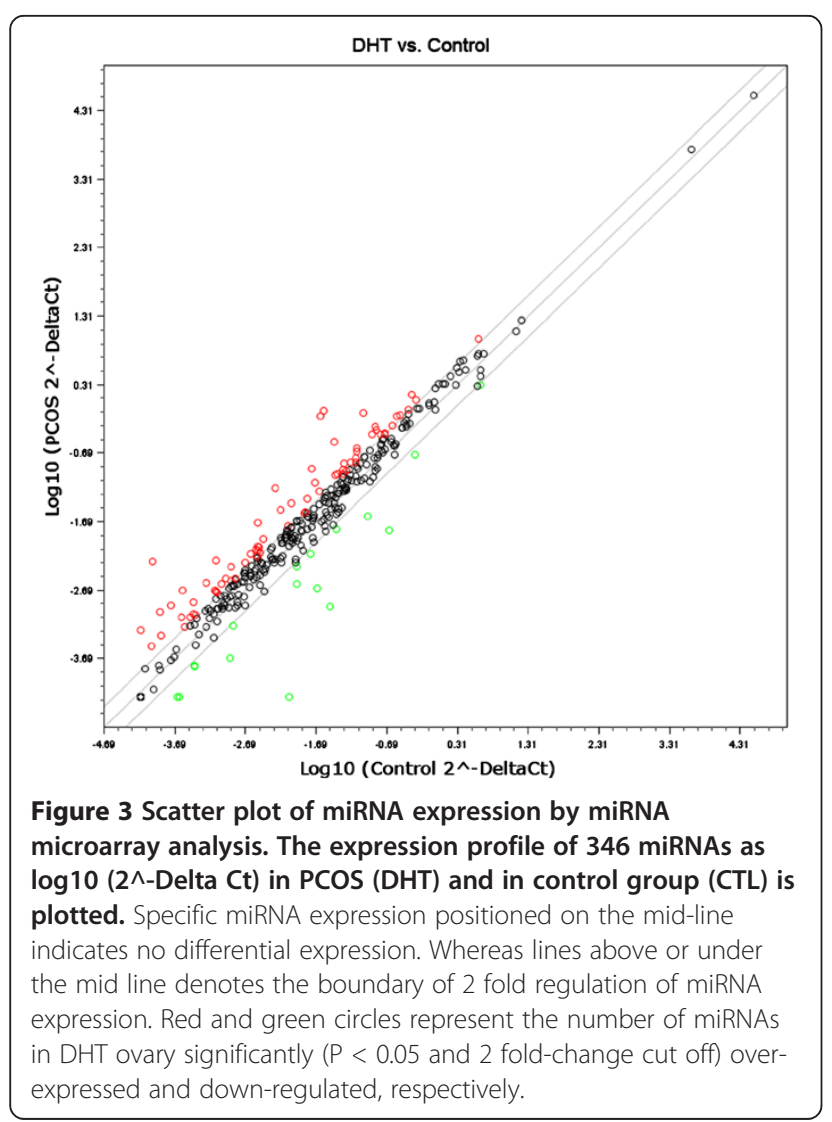

In situ localization of differentially expressed miRNAs in rat $\mathrm{PCOS}$

Cell-specific expression of differentially regulated miRNAs across different follicular stages in control and DHTtreated rats were compared by in situ localization (Figure 5). These included rno-miR-24, rno-miR-31, rno-miR-96, rno-miR-183, rno-miR-222, rno-miR-489, U6 snRNA (positive control) and scrambled miRNA (negative control). Most of these miRNAs were localized in theca and granulosa cells as well as in oocytes at early stages of follicular development. Interestingly, miRNAs in the ovary undergoing or became cystic condition were differentially localized in the follicular cells in the advanced stages (Figure 5). Most of the miRNAs were localized in the follicular theca cells of DHT-treated ovaries. For example, rno-miR-96, rnomiR-31 and rno-miR-222 were exclusively expressed in

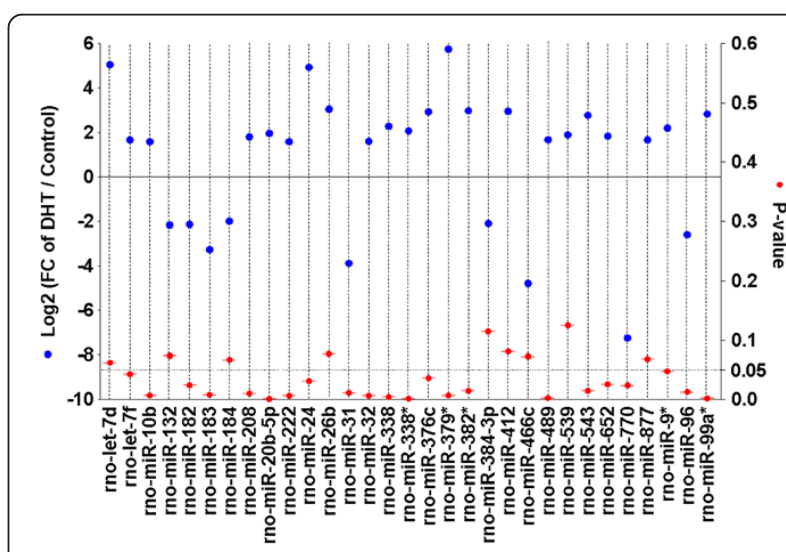

Figure 4 Plot diagram of the magnitude of fold regulation of most differentially regulated miRNAs in DHT ovary compared to control. The degree of expression difference by 2 or more fold regulation (log2 of Fold change of DHT/control: left $Y$ axis) is presented by blue circle with their corresponding P-value (red circle on the right $Y$ axis) of 31 screened miRNAs in DHT ovary compared to control. 


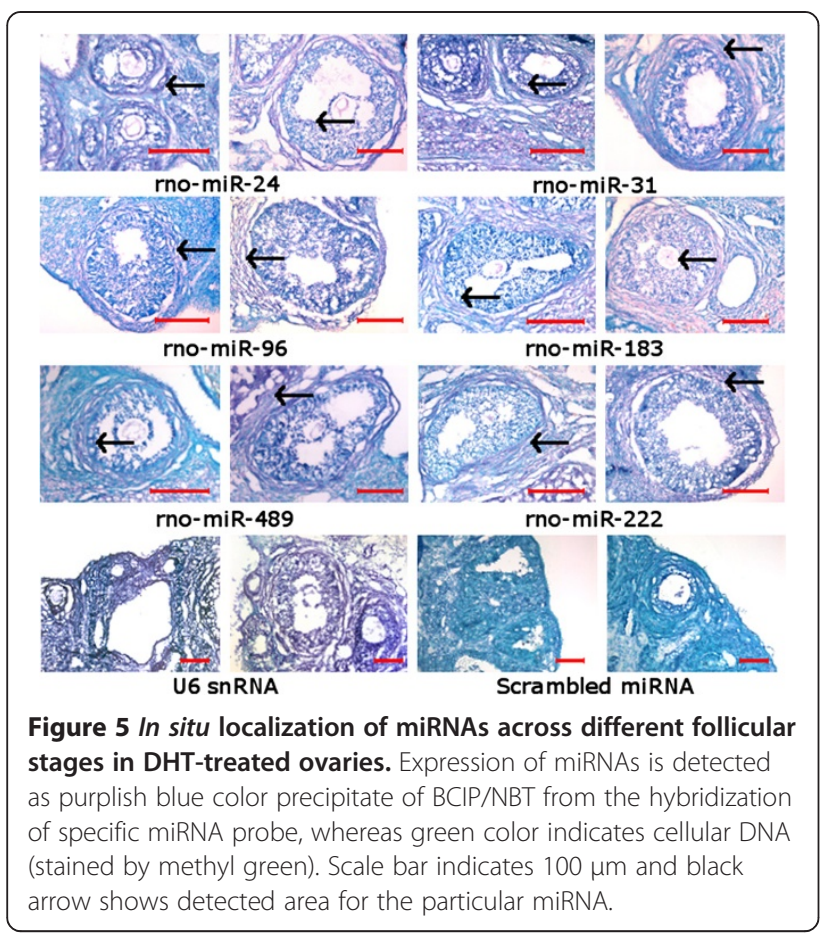

the theca of cystic follicles. Whereas rno-miR-24 and rno-miR-183 were highly expressed in the theca and, to a lesser extent, in the granulosa cells of the cystic follicles (Figure 5), Rno-miR-31 and rno-miR-96 were present in the cumulus granulosa cells. Occasionally, expression of rno-miR-489 was most noticeable in the theca and cumulus cells of FC. Thus, most of the differentially expressed miRNAs in the cystic ovary were predominantly localized in the theca cells.

\section{Functional classification of differentially expressed miRNA}

To explore and identify dysregulated molecular pathways resulting from altered miRNAs in DHT-treated ovaries, miRNAs highly enriched or markedly reduced in these ovaries were subjected to Ingenuity pathway analysis (IPA; http://www.ingenuity.com). MiRNA target genes and their respective molecular pathways were filtered and prioritized. Only highly predicted and experimentally validated targets were considered as the target genes of miRNA. Among the fourteen miRNAs mapped to the ingenuity databases, twelve (rno-let-7d, rno-miR-132, rno-miR-182, rno-miR-183, rno-miR-184, rno-miR-21, rno-miR-221, rno-miR-24, rno-miR-25, rno-miR-26b, rno-miR-31 and rno-miR-96) had 171 experimentally validated targets. When highly predicted genes were included to the outcome, a total of 2459 target genes were found to be targets of 14 differentially expressed miRNAs. The molecular pathways dysregulated by these differentially expressed miRNAs in DHT-treated ovaries was evaluated and included signalling by androgen, aldosterone, VEGF, FGF, growth hormone, 14-3-3, calcium, estrogen receptor, G-Protein coupled receptor, glucocorticoid receptor, and apoptosis as well as in ovarian cancer signalling and androgen and oestrogen metabolism (Table 1).

\section{Discussion}

PCOS is a complex and heterogeneous endocrine condition characterized by hyperandrogenemia, hyperinsulinemia, insulin resistance, and chronic anovulation. Using a rodent model for PCOS which recapitulates the reproductive and metabolic phenotypes of the human conditions [23], we have begun to examine molecular and cellular mechanisms underlying the dysregulated reproductive and metabolic functions of PCOS. We have demonstrated that chronically androgenised rats, exhibited increased body weight, disrupted estrus cyclicity, decreased insulin sensitivity and decreased ovarian weight. In the present study we have for the first time that these phenotypes are associated with dysregulation of gene regulatory noncoding miRNA.

Ovarian growth is the result of a series of complex and coordinated processes, which include morphological and functional changes in different follicular cells and their interactions. Among the small non-coding RNAs associated to various biological and physiological disorders (sncRNAs), miRNAs are the best characterized. Studies on the bovine and mouse ovary have demonstated the presence of miRNAs and suggested their potential role in ovarian functions $[10,29]$. Several intra-ovarian regulators and their receptors have been predicted as targets of this ovarian miRNAs, which mediate important intracellular events necessary for normal follicular development and functions.

Although miRNAs are expressed in the human, mouse and cow ovaries [10,14,29-34], little is known of their role and dysregulation in PCOS. The present study represents the first report on the dysregulation of miRNAs in a rat ovary chronically exposed to DHT, a condition mimicking the hyperandrogenic condition in human PCOS. Among the miRNAs examined, 79 miRNAs (24\%) responded to the hyperandrogenic condition and interestingly, $80 \%$ of which were upregulated compared to the control group supporting the notion that hyperandrogenic condition down-regulates androgen receptors in the granulosa cells [35] which could be mediated by these upregulated miRNAs (rno-miR-379*, rno-let-7d, rno-miR-24, rno-miR-673, rno-miR-26b, rno-miR-335, rno-miR-382*, rno-miR-412, rno-miR-99a*, rno-miR-543, rno-miR-674-3p, rno-miR-409-3p). It has been reported that the expression of miR-143, let-7a, miR-15b is under negative control of follicle stimulating hormone (FSH) during follicular development [36] and may be involved in 
Table 1 Molecular pathways regulated by miRNAs in DHT-treated ovaries

\begin{tabular}{|c|c|}
\hline Molecular pathways & List of miRNA \\
\hline Ovarian cancer signalling & 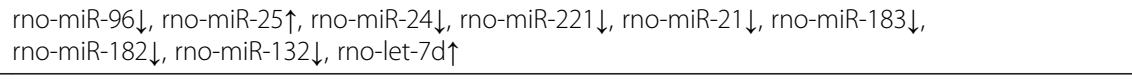 \\
\hline Androgen signalling & 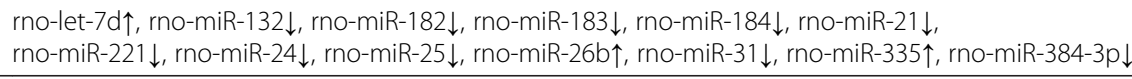 \\
\hline Androgen \& estrogen metabolism & 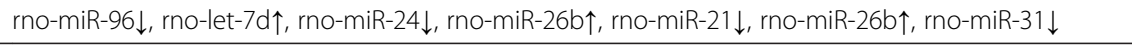 \\
\hline Aldosterone signalling (epithelial cells) & 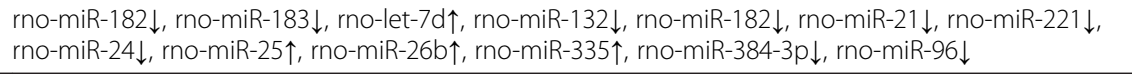 \\
\hline VEGF signalling & 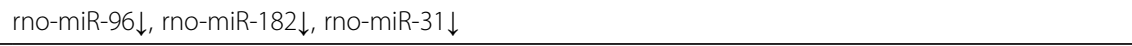 \\
\hline RhoA signalling & 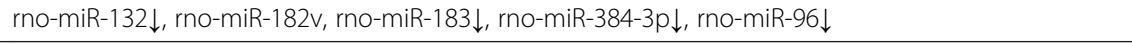 \\
\hline 14-3-3-mediated Signalling & 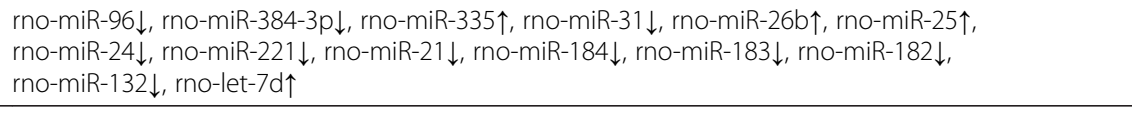 \\
\hline Apoptosis signalling & 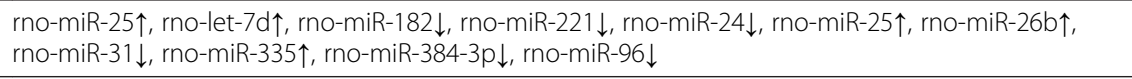 \\
\hline Calcium signalling & 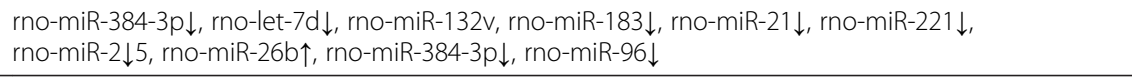 \\
\hline Estrogen receptor signalling & 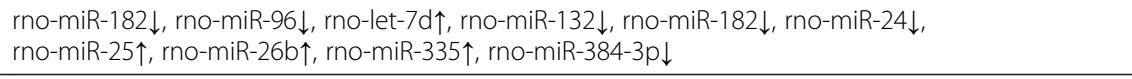 \\
\hline FGF Signalling & $\begin{array}{l}\text { rno-let-7d } \uparrow, \text { rno-miR-132 } \downarrow \text {, rno-miR-182 } \downarrow \text {, rno-miR-183 } \downarrow \text {, rno-miR-21 } \downarrow \text {, rno-miR-221 } \downarrow \text {, } \\
\text { rno-miR-384-3p } \downarrow \text {, rno-miR-96 }\end{array}$ \\
\hline G-Protein coupled receptor signalling & 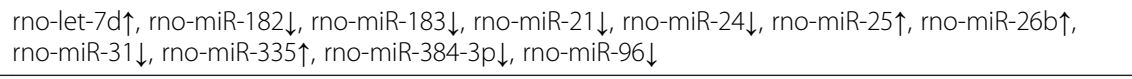 \\
\hline Focal adhesion kinase-1 (FAKn) & 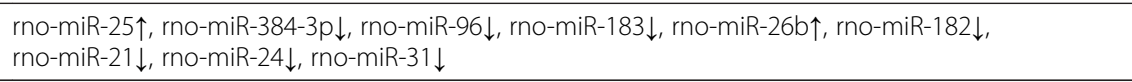 \\
\hline Glucocorticoid receptor Signalling & 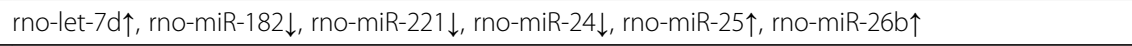 \\
\hline Growth hormone Signalling & 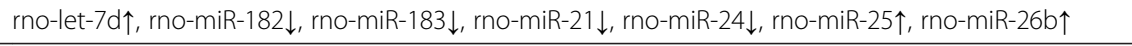 \\
\hline Inositol phosphate metabolism & 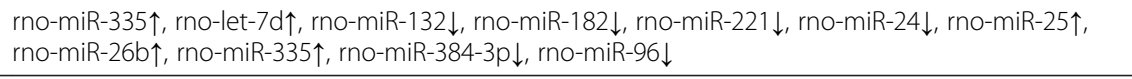 \\
\hline P53 signalling & 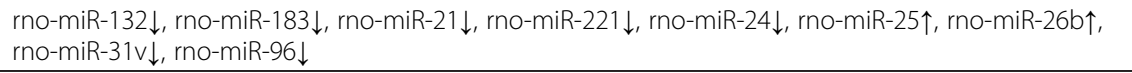 \\
\hline
\end{tabular}

FSH-induced rat granulosa cell progesterone production [37]. Thus, it is possible that the down-regulation of miRNAs (rno-miR-770, rno-miR-466c, rno-miR-31, rno-miR-183, rno-miR-96, rno-miR-132, rno-miR-182, rno-miR-384-3p and rno-miR-184) observed in this study could be associated with promoted thecal hyperandrogenesis [37,38]. Similarly, stepwise artificial neural networks analysis revealed predictive miRNA signatures (miR-342, miR-299, miR-217, miR-190, miR-135b, miR218) corresponding to oestrogen receptor status in breast cancer [39]. These findings raises the possibility that the modulated miRNA expression by exogenous DHT treatment activates estrogen receptors (ERs) to exert indirect steroidal actions on the follicular cells or directly on androgen receptor pathway for the regulation of androgen metabolism [40].

Recent evidences suggest that miRNAs are involved in the regulation of steroid hormone receptors (SHRs) in ovarian follicle growth and hormone-responsive cancers. Follicular development is the result of tightly regulated activities of FSH, estrogen, androgen and luteinizing hormone receptor (LHR) in granulosa and theca cells, as well as oocyte in response to hormonal stimulation and actions of intra-ovarian regulators [15]. MicroRNAs expression profile and analysis of their target genes revealed that microRNAs exhibits characteristics important in regulating downstream LHR signaling in ovarian cancer cells [41]. MiR-132, 5-fold down-regulation in DHT-treated group compared to control in this study, has previously been shown to be related to luteinizing hormones [12], raising the possibility that elevated LH in PCOS could involve the expression and action of miR-132.

Androgen Receptors (ARs) mRNA is predominantly expressed in rat granulosa cells and its expression decreases with the stage of follicle development [35]. Hyperandrogenemia induced by DHT is characterized by down-regulation of granulosa cell AR in rat preantral which could be restored by FSH administration [35]. Ovarian follicle expression of miR-221 and miR-222 has been reported to be repressed by androgens [42-44] which regulates cell proliferation by targeting p27/kip1 $[44,45]$. Here we observed higher expression of miR-222 in the DHT-induced PCOS rats, a response most 
evidenced in both theca and granulosa of early stage follicles. Interestingly, its expression pattern changes with increased follicular growth and antrum formation. In the cystic follicle, expression of miR-222 becomes restricted to theca only, suggesting that miR-222 modulates AR expression and hereby paracrine regulation.

Clinical studies have shown that follicular ER $\alpha$ and ER $\beta$ expression is significant altered in PCOS [46]. In breast cancer cells, over-expression of miR-221, miR-222, let-7 and miR-20b is associated with reduced of ER $\alpha$ protein content, signaling and expression of ER $\alpha$ target genes [47-49]. Our present study also showed higher expression of these miRNAs in the induced PCOS, consistent with a similar mechanism found in the breast cancer cells and their possible role in the regulation of ER $\alpha$ signaling. In situ localization shows specific expression of miR-222 in the theca cells (Figure 5) where it may be involved in regulation of the ER $\alpha$. In addition to miR-221/222, several studies also highlighted the differential regulation of let-7d, let-7f, miR-25 and miR-26b in prostate and breast cancer, as well as in leukemia by the estrogen receptor pathways and that their expression was upregulated in ER $\alpha$-positive cells [50-52]. Expression analysis of these miRNAs revealed their higher expression in PCOS, raising the possibility that estrogen-mediated regulation of these miRNAs might be involved in the etiology of PCOS. Unlike other miRNAs in DHTtreated PCOS rats, miR-183 was found to be highly expressed in granulosa cells of control ovaries but was down-regulated by 10 -fold in the PCOS counterpart. Interestingly, this miRNA was found to be correlated with estrogen receptor in breast cancer [53].

Hyperandrogenism in PCOS is one of the main causes for early follicle excess, which induces nuclear forkhead box transcription factors 3a (FOXO3a) exclusion and follicular arrest [54]. FOXO3a, a target of miR-96, promotes cancer cell proliferation [55]. Accordingly, expression of miR-96 in PCOS shows a 6-fold down-regulation compared to control ovary and is localized in the theca and cumulus-granulosa of cystic follicles. Thus, the cell proliferation in the preantral follicles in hyperandrogenic condition could be induced through a mechanism utilizing miR-96-mediated regulation.

PCOS is a complex syndrome with both reproductive and metabolic disorders. Although the rat PCOS model (DHT-treatment) simulates the hyperandrogenic state found in human PCOS and recapitulates some of the phenotypes of the human syndrome (obesity, disruption of menstrual cycle, insulin resistance), an inherent problem of any animal model for the complex syndrome is that it does not address all the phenotypes in PCOS. While the rat PCOS model may provide some mechanistic insight in the pathophysiology of the human syndrome, the significant findings from the animal studies need to be validated in the human context. In addition, although miRNAs are known to regulate multiple gene targets in different system $[56,57]$, they can also be regulated by other paracrine/ autocrine factors $[44,58]$. The precise target (s) for the reported dysregulated miRNA and their immediate downstream processes need to be defined.

In summary, using an androgenized rat model which recapitulates many of the reproductive and metabolic phenotypes of human PCOS, we have shown that miRNAs are differentially regulated in a follicular cellspecific manner. Since one given miRNA could target multiple mRNAs of different genes and a given target may be regulated by multiple miRNAs [59], whether these miRNAs involve in the dysregulation of the hormone receptors (AR, FSHR and ER) and intra-ovarian regulators of ovarian follicle growth and function in PCOS is unknown. The expression of predicted target genes and their regulation by these miRNAs needs to be clarified by further experiments. Our ongoing studies not only include target gene expression analysis but also their correlation with the miRNAs, and functional analysis. Taken together, the present findings support the notion that the present DHT-treated rat model is useful for investigating the role and regulation of miRNAs in the molecular and cellular mechanism of PCOS and may offer new insights for the treatment of reproductive and metabolic disorders associated to PCOS.

\section{Abbreviations}

PCOS: Polycystic ovarian syndrome; miRNA: microRNA; DHT:

5a-dihydrotestosterone; CL: Corpus luteum; CTL: Control; eCG: Equine chorionic gonadotropin; FC: Follicle cyst; AR: Androgen receptor; ER: Estrogen receptor; IST: Insulin sensitivity test; DIG: Digoxigenin; SSC: Sodium chloride/sodium citrate.

\section{Competing interests}

The authors declare that they have no competing interests

\section{Authors' contributions}

MMH, MJC, QW and JYK performed the experiments, prepared the data and drafted the manuscript. KS, DT and BKT are co-mentors, provided input of studies and edited the manuscript. All authors read and approved the final manuscript.

\section{Acknowledgements}

This work was supported by grants from the Canadian Institutes of Health Research (MOP-119381) and the World Class University (WCU) program through the Ministry of Education, Science and Technology and funded by the National Research Foundation of Korea (R31-10056) and research training awards [IHDCYH-STIRRHS Postdoctoral Fellowship (MJC), CIHR-QTNPR Doctoral Scholarship (QW) and CIHR-QTNPR Postdoctoral Fellowship (JYK)].

\section{Author details}

${ }^{1}$ Institute of Animal science, Animal Breeding and Husbandry Group, University of Bonn, Endenicher allee 15, Bonn 53115, Germany. ${ }^{2}$ Department of Animal Breeding and Genetics, Bangladesh Agricultural University, Mymensingh 2202, Bangladesh. ${ }^{3}$ Reproductive Biology Unit and Division of Reproductive Medicine, Department of Obstetrics \& Gynecology and Cellular \& Molecular Medicine, University of Ottawa; Chronic Disease Program, Ottawa Hospital Research Institute, The Ottawa Hospital (General Campus), Ottawa, ON K1H 8L6, Canada. ${ }^{4}$ World Class University Major in Biomodulation, Department of Agricultural Biotechnology, College of Agriculture and Life Sciences, Seoul National University, Seoul 151-921, 
Republic of Korea. ${ }^{5}$ Ottawa Hospital Research Institute, The Ottawa Hospital (General Campus), 501 Smyth Road, Mail Box \#511, Ottawa, ON K1H 8L6, Canada.

Received: 13 March 2013 Accepted: 6 May 2013

Published: 15 May 2013

\section{References}

1. Dunaif A: Insulin resistance and the polycystic ovary syndrome: mechanism and implications for pathogenesis. Endocr Rev 1997, 18:774-800.

2. Franks S: Polycystic ovary syndrome. N Engl J Med 1995, 333:853-861.

3. Legro RS, Barnhart HX, Schlaff WD, Carr BR, Diamond MP, Carson SA, Steinkampf MP, Coutifaris C, McGovern PG, Cataldo NA, Gosman GG, Nestler JE, Giudice LC, Leppert PC, Myers ER: Clomiphene, metformin, or both for infertility in the polycystic ovary syndrome. N Engl J Med 2007, 356:551-566.

4. Guzick DS: Polycystic ovary syndrome. Obstet Gynecol 2004, 103:181-193.

5. Diao FY, Xu M, Hu Y, Li J, Xu Z, Lin M, Wang L, Zhou Y, Zhou Z, Liu J, Sha J: The molecular characteristics of polycystic ovary syndrome (PCOS) ovary defined by human ovary cDNA microarray. J Mol Endocrinol 2004, 33:59-72.

6. Wood JR, Nelson VL, Ho C, Jansen E, Wang CY, Urbanek M, McAllister JM, Mosselman S, Strauss JF II: The molecular phenotype of polycystic ovary syndrome (PCOS) theca cells and new candidate PCOS genes defined by microarray analysis. J Biol Chem 2003, 278:26380-26390.

7. Hughes C, Elgasim M, Layfield R, Atiomo W: Genomic and post-genomic approaches to polycystic ovary syndrome-progress so far: Mini Review. Hum Reprod 2006, 21:2766-2775.

8. Wood JR, Ho CK, Nelson-Degrave VL, MCAllister JM, Strauss JF III: The molecular signature of polycystic ovary syndrome (PCOS) theca cells defined by gene expression profiling. J Reprod Immunol 2004, 63:51-60.

9. Wood JR, Dumesic DA, Abbott DH, Strauss JF III: Molecular abnormalities in oocytes from women with polycystic ovary syndrome revealed by microarray analysis. J Clin Endocrinol Metab 2007, 92:705-713.

10. Ro S, Song R, Park C, Zheng H, Sanders KM, Yan W: Cloning and expression profiling of small RNAs expressed in the mouse ovary. RNA 2007, 13:2366-2380.

11. Tang F, Kaneda M, O'Carroll D, Hajkova P, Barton SC, Sun YA, Lee C, Tarakhovsky A, Lao K, Surani MA: Maternal microRNAs are essential for mouse zygotic development. Genes Dev 2007, 21:644-648.

12. Fiedler SD, Carletti MZ, Hong X, Christenson LK: Hormonal regulation of MicroRNA expression in periovulatory mouse mural granulosa cells. Biol Reprod 2008, 79:1030-1037.

13. Zhao H, Rajkovic A: MicroRNAs and mammalian ovarian development Semin Reprod Med 2008, 26:461-468.

14. Sirotkin AV, Laukova M, Ovcharenko D, Brenaut P, Mlyncek M: Identification of microRNAs controlling human ovarian cell proliferation and apoptosis. J Cell Physiol 2009, 223:49-56.

15. Sirotkin AV, Ovcharenko D, Grossmann R, Laukova M, Mlyncek M: Identification of microRNAs controlling human ovarian cell steroidogenesis via a genome-scale screen. J Cell Physiol 2009, 219:415-420.

16. Alford C, Toloubeydokhti T, Al-Katanani Y, Drury KC, Williams R, Chenini N: The expression of microRNA (miRNA) mir-23a and 23b and their target gene, CYP19A1 (aromatase) in follicular cells obtained from women undergoing ART. Fertil Steril 2007, 88:S166-S167.

17. Toloubeydokhti T, Alford C, Al-Katanani Y, Luo X, Williams RS, Nasser C: The expression of microRNA (miRNA), mir-17, mir-211 and mir-542 and their target genes, StAR, IL-1 $\mathrm{b}$ and Cox2 in follicular cells derived from women undergoing ART. Fertil Steril 2007, 88:S165-S166.

18. Heneghan HM, Miller N, Kerin MJ: Role of microRNAs in obesity and the metabolic syndrome. Obes Rev 2010, 11:354-361.

19. Balen AH, Conway GS, Kaltsas G, Techatrasak K, Manning PJ, West C, Jacobs HS: Polycystic ovary syndrome: the spectrum of the disorder in 1741 patients. Hum Reprod 1995, 10:2107-2111

20. Wachs DS, Coffler MS, Malcom PJ, Shimasaki S, Chang RJ: Increased androgen response to follicle-stimulating hormone administration in women with polycystic ovary syndrome. J Clin Endocrinol Metab 2008, 93:1827-1833.

21. Motta AB: Dehydroepiandrosterone to induce murine models for the study of polycystic ovary syndrome. J Steroid Biochem Mol Biol 2010, 119:105-111.

22. Singh KB: Rat models of polycystic ovary syndrome. In Sourcebook of models for biomedical research. Edited by Conn PM. Totowa, New Jersey: Humana Press Inc; 2008:405-410.
23. Manneras L, Cajander S, Holmang A, Seleskovic Z, Lystig T, Lonn M, StenerVictorin E: A new rat model exhibiting both ovarian and metabolic characteristics of polycystic ovary syndrome. Endocrinology 2007, 148:3781-3791.

24. Brawer J, Schipper H, Robaire B: Effects of long term androgen and estradiol exposure on the hypothalamus. Endocrinology 1983, 112:194-199.

25. Marcondes FK, Bianchi FJ, Tanno AP: Determination of the estrous cycle phases of rats: some helpful considerations. Braz I Biol 2002, 62:609-614

26. Anwer T, Sharma M, Pillai KK, labal M: Effect of Withania somnifera on insulin sensitivity in non-insulin-dependent diabetes mellitus rats. Basic Clin Pharmacol Toxicol 2008, 102:498-503.

27. Tilly JL: Ovarian follicle counts-not as simple as 1, 2, 3. Reprod Biol Endocrinol 2003, 1:11

28. Obernosterer G, Martinez J, Alenius M: Locked nucleic acid-based in situ detection of microRNAs in mouse tissue sections. Nat Protoc 2007, 2:1508-1514.

29. Hossain MM, Ghanem N, Hoelker M, Rings F, Phatsara C, Tholen E, Schellander K, Tesfaye D: Identification and characterization of miRNAs expressed in the bovine ovary. BMC Genomics 2009, 10:443.

30. Dahiya N, Sherman-Baust CA, Wang TL, Davidson B, Shih le M, Zhang Y, Wood W III, Becker KG, Morin PJ: MicroRNA expression and identification of putative miRNA targets in ovarian cancer. PLoS One 2008, 3:e2436.

31. Giannakakis A, Sandaltzopoulos R, Greshock J, Liang S, Huang J, Hasegawa K, Li C, O'Brien-Jenkins A, Katsaros D, Weber BL, Simon C, Coukos G, Zhang L: miR-210 links hypoxia with cell cycle regulation and is deleted in human epithelial ovarian cancer. Cancer Biol Ther 2008, 7:255-264.

32. Laios A, O'Toole S, Flavin R, Martin C, Kelly L, Ring M, Finn SP, Barrett C, Loda M, Gleeson N, D'Arcy T, McGuinness E, Sheils O, Sheppard B, O'Leary J: Potential role of miR-9 and miR-223 in recurrent ovarian cancer. Mol Cancer 2008, 7:35.

33. Nam EJ, Yoon H, Kim SW, Kim H, Kim YT, Kim JH, Kim JW, Kim S: MicroRNA expression profiles in serous ovarian carcinoma. Clin Cancer Res 2008, 14:2690-2695

34. Zhang L, Volinia S, Bonome T, Calin GA, Greshock J, Yang N, Liu CG, Giannakakis A, Alexiou P, Hasegawa K, Johnstone CN, Megraw MS, Adams S, Lassus H, Huang J, Kaur S, Liang S, Sethupathy P, Leminen A, Simossis VA, Sandaltzopoulos R, Naomoto Y, Katsaros D, Gimotty PA, DeMichele A, Huang Q, Butzow R, Rustgi AK, Weber BL, Birrer MJ, Hatzigeorgiou AG, Croce CM, Coukos G: Genomic and epigenetic alterations deregulate microRNA expression in human epithelial ovarian cancer. Proc Natl Acad Sci U S A 2008, 105:7004-7009.

35. Tetsuka M, Hillier SG: Androgen receptor gene expression in rat granulosa cells: the role of follicle-stimulating hormone and steroid hormones. Endocrinology 1996, 137:4392-4397.

36. Yao N, Lu CL, Zhao JJ, Xia HF, Sun DG, Shi XQ, Wang C, Li D, Cui Y, Ma X: A network of miRNAs expressed in the ovary are regulated by FSH. Front Biosci 2009, 14:3239-3245.

37. Yao N, Yang BQ, Liu Y, Tan XY, Lu CL, Yuan XH, Ma X: Follicle-stimulating hormone regulation of microRNA expression on progesterone production in cultured rat granulosa cells. Endocrine 2010, 38:158-166

38. Cardenas H, Herrick JR, Pope WF: Increased ovulation rate in gilts treated with dihydrotestosterone. Reproduction 2002, 123:527-533.

39. Lowery AJ, Miller N, Devaney A, McNeill RE, Davoren PA, Lemetre C, Benes V, Schmidt S, Blake J, Ball G, Kerin MJ: MicroRNA signatures predict oestrogen receptor, progesterone receptor and HER2/neu receptor status in breast cancer. Breast Cancer Res 2009, 11:R27.

40. Mercier L, le Guellec C, Thieulant ML, Samperez S, Jouan P: Androgen and estrogen receptors in the cytosol from male rat anterior hypophysis: further characteristics and differentiation between androgen and estrogen receptors. J Steroid Biochem 1976, 7:779-785.

41. Cui J, Eldredge JB, Xu Y, Puett D: MicroRNA expression and regulation in human ovarian carcinoma cells by luteinizing hormone. PLoS One 2011, 6:e21730.

42. Chen Y, Robles Al, Martinez LA, Liu F, Gimenez-Conti IB, Conti CJ: Expression of G1 cyclins, cyclin-dependent kinases, and cyclindependent kinase inhibitors in androgen-induced prostate proliferation in castrated rats. Cell Growth Differ 1996, 7:1571-1578.

43. Mercatelli N, Coppola V, Bonci D, Miele F, Costantini A, Guadagnoli M, Bonanno E, Muto G, Frajese GV, De Maria R, Spagnoli LG, Farace MG, Ciafre SA: The inhibition of the highly expressed miR-221 and miR-222 impairs the growth of prostate carcinoma xenografts in mice. Plos One 2008, 3:e4029. 
44. Sun T, Wang Q, Balk S, Brown M, Lee GS, Kantoff P: The role of microRNA221 and microRNA-222 in androgen-independent prostate cancer cell lines. Cancer Res 2009, 69:3356-3363.

45. Galardi S, Mercatelli N, Giorda E, Massalini S, Frajese GV, Ciafre SA, Farace MG: miR-221 and miR-222 expression affects the proliferation potential of human prostate carcinoma cell lines by targeting p27Kip1. J Biol Chem 2007, 282:23716-23724.

46. Jakimiuk AJ, Weitsman SR, Yen HW, Bogusiewicz M, Magoffin DA: Estrogen receptor alpha and beta expression in theca and granulosa cells from women with polycystic ovary syndrome. J Clin Endocrinol Metab 2002, 87:5532-5538

47. Castellano L, Giamas G, Jacob J, Coombes RC, Lucchesi W, Thiruchelvam P, Barton G, Jiao LR, Wait R, Waxman J, Hannon GJ, Stebbing J: The estrogen receptor-alpha-induced microRNA signature regulates itself and its transcriptional response. Proc Natl Acad Sci U S A 2009, 106:15732-15737.

48. Zhao JJ, Lin J, Yang H, Kong W, He L, Ma X, Coppola D, Cheng JQ: MicroRNA-221/222 negatively regulates estrogen receptor alpha and is associated with tamoxifen resistance in breast cancer. J Biol Chem 2008, 283:31079-31086.

49. Zhao Y, Deng C, Wang J, Xiao J, Gatalica Z, Recker RR, Xiao GG: Let-7 family miRNAs regulate estrogen receptor alpha signaling in estrogen receptor positive breast cancer. Breast Cancer Res Treat 2010, 127:69-80.

50. Blenkiron C, Goldstein LD, Thorne NP, Spiteri I, Chin SF, Dunning MJ, Barbosa-Morais NL, Teschendorff AE, Green AR, Ellis IO, Tavare S, Caldas C, Miska EA: MicroRNA expression profiling of human breast cancer identifies new markers of tumor subtype. Genome Biol 2007, 8:R214.

51. Kovalchuk O, Tryndyak VP, Montgomery B, Boyko A, Kutanzi K, Zemp F, Warbritton AR, Latendresse JR, Kovalchuk I, Beland FA, Pogribny IP: Estrogen-induced rat breast carcinogenesis is characterized by alterations in DNA methylation, histone modifications and aberrant microRNA expression. Cell Cycle 2007, 6:2010-2018.

52. Mattie MD, Benz CC, Bowers J, Sensinger K, Wong L, Scott GK, Fedele V, Ginzinger D, Getts R, Haqq C: Optimized high-throughput microRNA expression profiling provides novel biomarker assessment of clinical prostate and breast cancer biopsies. Mol Cancer 2006, 5:24.

53. Lowery AJ, Miller N, Dwyer RM, Kerin MJ: Dysregulated miR-183 inhibits migration in breast cancer cells. BMC Cancer 2010, 10:502.

54. Yang JL, Zhang CP, Li L, Huang L, Ji SY, Lu CL, Fan CH, Cai H, Ren Y, Hu ZY, Gao F, Liu YX: Testosterone induces redistribution of forkhead box-3a and down-regulation of growth and differentiation factor 9 messenger ribonucleic acid expression at early stage of mouse folliculogenesis. Endocrinology 2010, 151:774-782.

55. Lin H, Dai T, Xiong H, Zhao X, Chen X, Yu C, Li J, Wang X, Song L: Unregulated miR-96 induces cell proliferation in human breast cancer by downregulating transcriptional factor FOXO3a. PLoS One 2010, 5:e15797.

56. Bartel DP: MicroRNAs: genomics, biogenesis, mechanism, and function. Cell 2004, 116:281-297.

57. Toloubeydokhti T, Bukulmez O, Chegini N: Potential regulatory functions of microRNAs in the ovary. Semin Reprod Med 2008, 26:469-478.

58. Sun Q, Zhang Y, Yang G, Chen X, Cao G, Wang J, Sun Y, Zhang P, Fan M, Shao $\mathrm{N}$, Yang X: Transforming growth factor-beta-regulated miR-24 promotes skeletal muscle differentiation. Nucleic Acids Res 2008, 36:2690-2699.

59. Krek A, Grün D, Poy MN, Wolf R, Rosenberg L, Epstein EJ, MacMenamin P, da Piedade I, Gunsalus KC, Stoffel M, Rajewsky N: Combinatorial microRNA target predictions. Nat Genet 2005, 37:495-500.

doi:10.1186/1757-2215-6-36

Cite this article as: Hossain et al: Altered expression of miRNAs in a dihydrotestosterone-induced rat PCOS model. Journal of Ovarian Research 2013 6:36.

\section{Submit your next manuscript to BioMed Central and take full advantage of:}

- Convenient online submission

- Thorough peer review

- No space constraints or color figure charges

- Immediate publication on acceptance

- Inclusion in PubMed, CAS, Scopus and Google Scholar

- Research which is freely available for redistribution

Submit your manuscript at www.biomedcentral.com/submit
Ciomed Central 